\title{
Prognostic stratification of patients after myocardial infarction
}

\author{
DONAL P MURRAY, MAHMOOD SALIH, LIP BUN TAN, \\ R GORDON MURRAY, WILLIAM A LITTLER
}

From the Department of Cardiovascular Medicine, University of Birmingham, East Birmingham Hospital, Birmingham

SUMMARY An attempt was made to stratify risk of subsequent cardiac events in post-infarct patients according to a combination of the results of clinical assessment, routine diagnostic investigations, and pre-discharge exercise testing in 350 consecutive patients who were followed up for one year. Patients were classified prospectively on the basis of the extent of myocardial damage as assessed by peak enzyme release, reciprocal change on the electrocardiogram at the time of myocardial infarction, Norris prognostic index, ability to perform a pre-discharge exercise test (and test result), and ability to tolerate $\beta$ adrenergic blockade on discharge. Of the 50 patients with contraindications to pre-discharge exercise testing, $26 \%$ died or had reinfarctions compared with $9 \%$ of the 300 exercised patients; the 24 non-exercised patients with evidence of extensive myocardial damage or reciprocal changes on the electrocardiogram were particularly at risk. Similarly, among the 300 exercised patients, extensive myocardial damage, reciprocal change on the electrocardiogram, and ST depression on exercise testing were the major risk markers in that each identified at least $75 \%$ of the patients who had subsequent cardiac events. The 63 exercised patients who had all three of these major risk markers constituted a high risk group: $18(29 \%)$ died or had reinfarction. Of the remaining 237 patients, only $9(4 \%)$ had cardiac events. The 35 high risk patients with exercise induced angina pectoris or clinical contraindications to $\beta$ blockade were particularly at risk; $15(43 \%)$ died or had reinfarction.

This approach to risk stratification identified a small cohort of high risk patients in a large population of myocardial infarction survivors; it also identified a large group with a very low risk of subsequent cardiac events.

The prognosis after recovery from acute myocardial infarction is chiefly related to two factors; namely the degree of damage to the left ventricle at the time of infarction and the amount of myocardium still at risk because it is supplied by critically diseased coronary arteries. ${ }^{1-3}$ It is not surprising, therefore, that an array of historical, clinical, and exercise variables have been identified as markers of increased risk for the post-infarct patient. ${ }^{4-6}$ All of these risk factors when used in isolation lack specificity-they all produce a large proportion of false positive results. ${ }^{78}$

The aim of this study was, therefore, to stratify our post-infarct population into risk categories by combining the results of clinical assessment of the

Requests for reprints to Dr Donal P Murray, Department of Medicine, Cork Regional Hospital, Wilton, Cork, Ireland.

Accepted for publication 2 December 1986 patient, routine diagnostic investigations, and predischarge exercise testing.

\section{Patients and methods}

STUDY POPULATION

Over an 18 month period we studied all patients aged less than 66 years who survived to discharge from our coronary care unit. Those with electrocardiographic and enzymatic evidence of myocardial infarction were enrolled in the study. ${ }^{9}$ There were 350 patients who fulfilled the entry criteria. The mean (SD) age of the study population was 53(3) years and the male:female ratio was 499:1. Of the 350 patients, 50 did not perform a pre-discharge exercise test: 38 because of heart failure, seven because of other serious medical conditions, three for logistical reasons, and two refused to exercise. 


\section{FOLLOW UP}

All patients were regularly followed up in our cardiology clinic. The mean duration of follow up was 13 months, and all patients were followed for at least six months. During the follow up period 23 patients died, 34 had a further myocardial infarction, and 40 patients had one or other of these cardiac events. All the deaths were cardiac, occurring either suddenly at home or in association with a recurrent infarction.

\section{DRUG TREATMENT}

At the time of exercise 62 patients were taking a $\beta$ adrenergic blocker, and after discharge all patients were prescribed metoprolol (100 mg twice a day) for secondary prevention unless this treatment was clinically contraindicated. In total, 90 patients were not given a $\beta$ blocker: 60 because of heart failure, 14 because of peripheral vascular disease, four because of heart block, and 12 because of other serious medical conditions.

\section{VARIABLES STUDIED}

During the in-hospital period the following variables were recorded on all patients: Norris prognostic index; reciprocal changes on the electrocardiogram; the degree of left ventricular damage; the results of a pre-discharge exercise test; the prescription of a $\beta$ adrenergic blocker on discharge.

\section{Norris prognostic index}

Each patient's Norris prognostic index was computed by giving a weighted score for age, history of ischaemia, radiological heart size, and evidence of cardiac failure on the day of admission. Norris et al have previously demonstrated increasing mortality with increasing index. ${ }^{4}$ Patients were subdivided by median Norris index into groups with high and low values.

\section{Reciprocal changes}

Myocardial infarct regions were defined as follows: in anterior infarction changes were seen in leads V1-V5; in inferior infarction in leads II, III, and aVF; and lateral infarction was defined as changes in leads I, aVL, and V6. Reciprocal changes were defined as the presence of $>0.1 \mathrm{mV}$ of horizontal or downsloping ST depression which extended for 80 ms beyond the $J$ point of the electrocardiogram in leads remote from the site of infarction.

\section{Myocardial damage}

Extensive myocardial damage was defined as a peak enzyme release in excess of five times the upper limit of normal for our laboratory-that is a peak serum aspartate transaminase $>200$ IU or a peak lactate

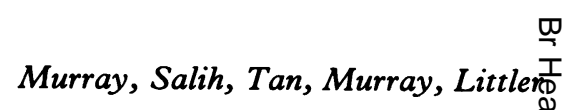
dehydrogenase $>2000$ IU. In the absence of either of these findings, a history of previous myocardiaf: infarction was also taken to indicate severe left ven tricular damage.

Exercise test

Treadmill exercise testing was carried out on the dayळ of discharge from hospital according to a modified Naughton's protocol..$^{10}$ Exercise was stopped at $18^{\mathrm{N}}$ minutes ( 7 metabolic equivalents of energy $\overrightarrow{0}$ expenditure at rest) or earlier if the patient devel- $\overrightarrow{\vec{\omega}}$ oped limiting symptoms, significant ventricular $\omega$ arrhythmias, $>0.4 \mathrm{mV}$ of ST depression, or a fall in systolic blood pressure of $20 \mathrm{~mm} \mathrm{Hg}$ or more fromer the previous peak systolic value.

Tests were classified as positive if there was more than $0.1 \mathrm{mV}$ of horizontal or downsloping ST seg- $\vec{\omega}$ ment depression which extended for $80 \mathrm{~ms}$ beyondo the $J$ point of the electrocardiogram or if the patienthad an abnormal blood pressure response to $D$ exercise-that is, failure of the systolic blood pressure to rise from the resting value or a fall in the $\vec{c}$ systolic blood pressure of $10 \mathrm{~mm} \mathrm{Hg}$ or more from the previous peak systolic value.

In addition, the presence or absence of exerciseo induced angina pectoris was noted in all patients. In view of the lack of objectivity of this symptom, how-o ever, it was not used to classify tests as positive or요 negative.

\section{$\beta$ blocker prescription}

As cardiac failure was the most common contra indication to $\beta$ blockade in our population, it seemed? likely that patients who were not taking $\beta$ blockers would constitute a high risk group. Presence or absence of $\beta$ blockade on discharge was, therefore, noted in all patients.

STATISTICAL ANALYSIS

Student's $t$ test was used to assess differenceso between means of independent observations. The $\chi^{2} D$ test was used to assess differences between propor-을. tions. In the text and tables mean (SD) values are given.

\section{Results}

Table 1 demonstrates the ability of each of the risko markers to identify those patients who died or had aD reinfarction. The median Norris index of the tota ${ }^{\text {f }}$ population of 350 patients was $4 \cdot 81$. There was no difference in the frequency of subsequent cardiag events when the patients were subdivided on the? basis of the median index. Similarly, stratification of the patients into centiles on the basis of the Norris index failed to identify cohorts that were at 
Table 1 Ability of the risk markers to identify from the total population of 350 patients those who died or had a reinfarction (RI)

\begin{tabular}{|c|c|c|c|c|c|}
\hline \multirow[b]{2}{*}{ Marker } & \multicolumn{2}{|c|}{ Risk marker positive } & \multicolumn{2}{|c|}{ Risk marker negative } & \multirow[b]{2}{*}{$p$} \\
\hline & Total & $\operatorname{Death} / R I(\%)$ & Total & Death $/ R I(\%)$ & \\
\hline $\begin{array}{l}\text { Norris index > median } \\
\text { Reciprocal change } \\
\text { Extensive myocardial damage } \\
\text { No exercise test } \\
\text { No } \beta \text { blocker }\end{array}$ & $\begin{array}{r}175 \\
204 \\
171 \\
50 \\
90\end{array}$ & $\begin{array}{l}21(12) \\
33(33) \\
31(18) \\
13(26) \\
23(26)\end{array}$ & $\begin{array}{l}175 \\
146 \\
179 \\
300 \\
260\end{array}$ & $\begin{array}{l}19(11) \\
7(5) \\
9(5) \\
27(9) \\
17(7)\end{array}$ & $\begin{array}{l}\text { NS } \\
\star \star \\
\star \star \star \\
\star \star \star \\
\star \star \star\end{array}$ \\
\hline
\end{tabular}

${ }^{\star \star} \mathrm{p}<0.01,{ }^{\star \star \star} \mathrm{p}<0.001$.

Table 2 Ability of the risk markers to identify from among the 300 exercised patients those who died or had a reinfarction (RI)

\begin{tabular}{|c|c|c|c|c|c|}
\hline \multirow[b]{2}{*}{ Marker } & \multicolumn{2}{|c|}{ Risk marker positive } & \multicolumn{2}{|c|}{ Risk marker negative } & \multirow[b]{2}{*}{$p$} \\
\hline & Total & Death $/ R I(\%)$ & Total & Death/RI $(\%)$ & \\
\hline $\begin{array}{l}\text { Norris index }>\text { median } \\
\text { Reciprocal change } \\
\text { Extensive myocardial damage } \\
\text { Positive exercise test } \\
\text { Exercise induced angina } \\
\text { No } \beta \text { blocker }\end{array}$ & $\begin{array}{r}150 \\
172 \\
135 \\
170 \\
78 \\
42\end{array}$ & $\begin{array}{l}12(8) \\
23(13) \\
21(16) \\
23(14) \\
16(21) \\
11(26)\end{array}$ & $\begin{array}{l}150 \\
128 \\
165 \\
130 \\
195 \\
258\end{array}$ & $\begin{array}{l}15(10) \\
4(3) \\
6(4) \\
4(2) \\
11(6) \\
16(6)\end{array}$ & $\begin{array}{l}\text { NS } \\
\star \star \\
\star \star \star \\
\star \star \\
\star \star \\
\star \star\end{array}$ \\
\hline
\end{tabular}

$\star \star \mathrm{p}<0.01 ;{ }^{\star \star \star} \mathrm{p}<0.001$.

increased risk. Patients with reciprocal changes at the time of infarction had a higher frequency of death and re-infarction than the group without this finding $(p<0.01)$. Similarly, those with severe myocardial damage, those judged unfit to perform a pre-discharge exercise test, and those judged unlikely to tolerate long term $\beta$ blockade were all at increased risk of death or reinfarction compared with patients who did not have these risk markers $(\mathrm{p}<0.001)$.

One hundred and thirty four $(70 \%)$ of the 172 patients with reciprocal changes also developed ST depression on exercise. Among the 300 exercised patients, those with reciprocal changes, extensive myocardial damage, a positive exercise test or exercise induced angina, and patients judged unlikely to tolerate a $\beta$ blocker were all at increased risk of death and reinfarction $(p<0.01$; table 2$)$. Among the exercised patients, the presence of reciprocal changes, extensive myocardial damage, and positive exercise test were the most sensitive risk markers;

Table 3 Clinical outcome for the high and low risk patients

\begin{tabular}{llll}
\hline Outcome & $\begin{array}{c}\text { High risk } \\
(n=63)\end{array}$ & $\begin{array}{l}\text { Low risk } \\
(n=237)\end{array}$ & $p$ \\
\hline Death (14) & $11(17 \%)$ & $3(1 \%)$ & $\star \star \star$ \\
RI (24) & $17(27 \%)$ & $7(3 \%)$ & $\star \star \star$ \\
Death or RI (27) & $18(29 \%)$ & $9(4 \%)$ & $\star \star \star$ \\
\hline
\end{tabular}

High risk $=$ positive exercise test, reciprocal changes . on the electrocardiogram, and extensive myocardial damage.

Low risk = patients who did not have all three major risk markers. $\star \star \star p<0.001$. RI, reinfarction. each identified more than 20 of the 27 patients who died or had reinfarction. Sixty three of the exercised patients had all three of these risk markers-that is, reciprocal changes, extensive myocardial damage, and a positive exercise test result. Eighteen $(67 \%)$ of the 27 patients who died or had reinfarction fell into this high risk group ( $<<0.001$; table 3$)$.

Thirty five of the 63 high risk patients had exercise induced angina pectoris or were judged unlikely to tolerate long term $\beta$ blockade (figure). This subgroup contained 15 of the 18 high risk patients who had complications. Only three $(11 \%)$ of the 28 remaining high risk patients died or had reinfarction ( $\mathrm{p}<0.01$; figure).

Among the 50 patients unable to perform a predischarge exercise test, $10(42 \%)$ of the 24 with severe left ventricular damage and reciprocal changes had complications compared with three $(12 \%)$ of the 26 without both of these markers ( $p<0.05$; figure). Only two of the 50 non-exercised patients were prescribed a $\beta$ blocker on discharge.

\section{Discussion}

Our results demonstrate that by combining the results of clinical assessment, routine diagnostic investigations, and pre-discharge exercise testing we could identify with a high degree of accuracy those infarct survivors who were at high risk of death and reinfarction during the next year. Most of our patients constituted a low risk group and had a good prognosis. Reciprocal changes on the electrocardiogram at the time of infarction, evidence of 


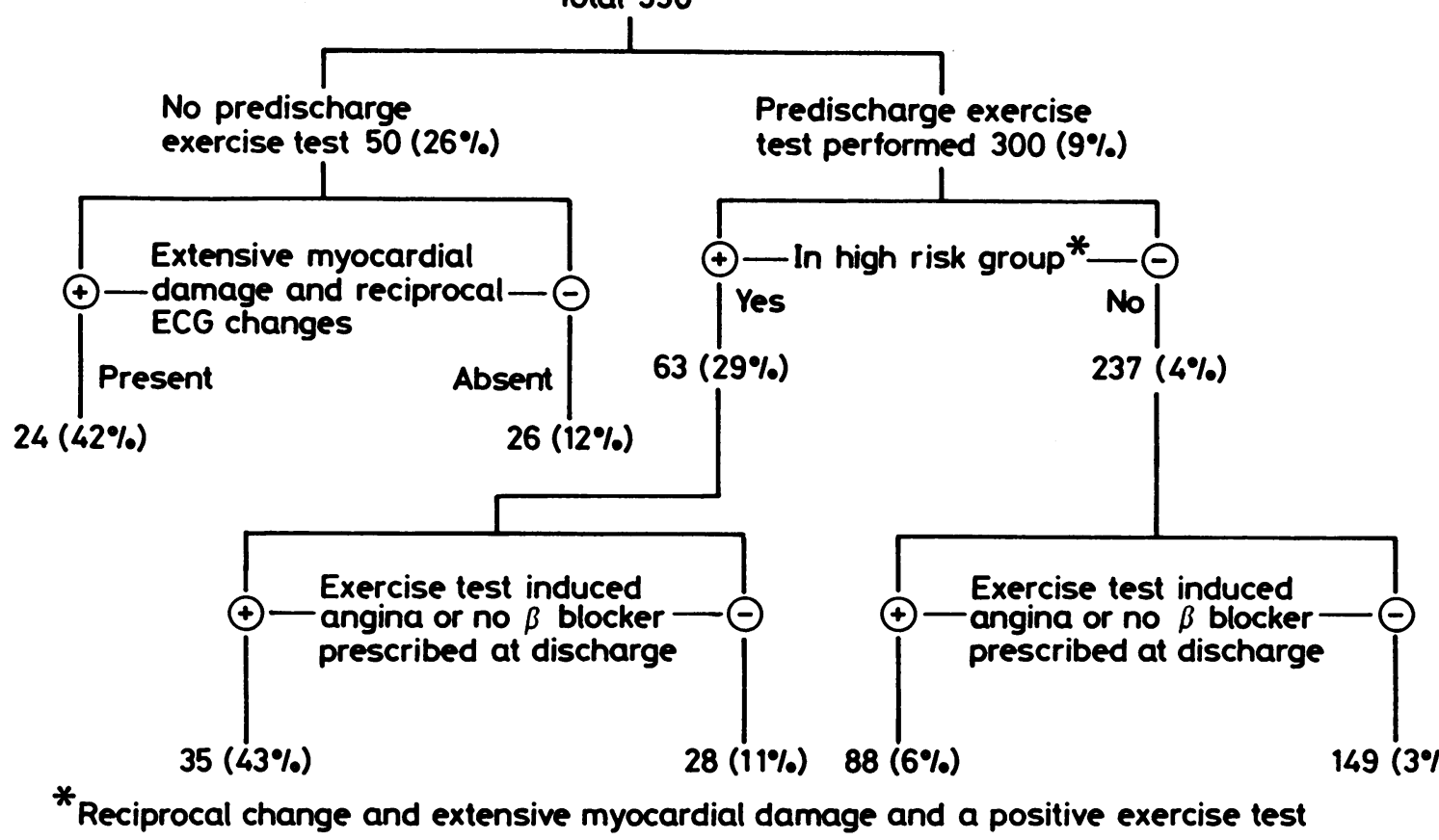

Figure Subdivision of patients according to clinical and exercise test results. The figures in parentheses are percentages of eac group who died or had a reinfarction.

severe myocardial damage, inability to perform a pre-discharge exercise test or to tolerate $\beta$ blockade, and a positive exercise test or exercise induced angina pectoris were all significantly associated with a poor prognosis.

When individual risk markers are used in postinfarct patients they lack specificity. This lack of specificity is evident from our results and those of other investigators. Geltman et al and Sobel et al demonstrated that patients with large infarcts, as assessed by peak enzyme release, had a worse long term prognosis than patients with a small peak enzyme release. ${ }^{111}$ None the less, $70 \%$ of their patients with large infarcts survived more than four years. Similarly, $82 \%$ of our patients with evidence of severe myocardial damage had no complications during our one year follow up.

Hlatky et al reported an $80 \%$ five year survival rate in their patients with reciprocal changes on the electrocardiogram at the time of infarction compared with $92 \%$ in those patients without such changes. ${ }^{8}$ Similar results were reported by Geltman et al. ${ }^{1}$ These results are again consistent with ours: although we found reciprocal change to be a significant marker of increased risk $84 \%$ of our patients with this finding had no complications.

Many workers have noted that patients considered to be medically ineligible for pre-discharge exercise testing have a bad prognosis. ${ }^{5712}$ Our non- exercised patients were also at increased risk, yê only $26 \%$ had complications. In the papers that have demonstrated increased risk in patients with positive pre-discharge exercise tests, the frequency of com plications was still relatively low: DeBusk et $(9.7 \%),{ }^{5}$ Sami et al $(22 \%),{ }^{13}$ and Theroux et al $(27 \%){ }^{6}$ These results are consistent with our figure of $14 \%$. Similarly, despite the value of exercisez induced angina pectoris as a risk marker, $74 \%$ of the Montreal patients ${ }^{6}$ and $79 \%$ of our patients with. this finding had no complications during the on 8 year follow up.

In the Norwegian multicentre study of timolog after acute myocardial infarction $40 \%$ of those excluded from the study because of medical con traindications died during the next six months. This figure is comparable with the $26 \%$ incidence of complications in our patients who were not treated with $\beta$ blockers.

It is clear, therefore, that, in keeping with oth investigators, we were able to identify several statis tically significant risk markers in a post-infarct popt ulation. When used individually these risk markers lacked specificity. Combining them enabled us to identify with a greater degree of accuracy thos patients who were at risk of death or reinfarction. If the group of 50 patients considered to be medicali ineligible for exercise testing 10 of the 13 who dever oped complications were included in the subgroup 
of 24 who also had reciprocal changes and severe left ventricular damage. No study had previously attempted to further stratify, on a prognostic basis, patients judged ineligible for pre-discharge exercise testing. The prognostic implications of a positive exercise test were greatly increased by the presence of reciprocal changes and severe left ventricular damage. Conversely, only $4 \%$ of the 237 patients who did not have all three major risk factors had complications $(p<0.001)$. Although exercise induced angina pectoris and inability to tolerate long term $\beta$ blockade were significant markers of increased risk, when they were used individually they identified only a small proportion of those patients who died or had a reinfarction. In combination they facilitated further prognostic stratification of the high risk patients. DeBusk et al had previously identified high risk groups in a post-infarct population on the basis of past history, ineligibility for pre-discharge exercise testing, and exercise test results. ${ }^{5}$ In that study, however, none of the patients identified clinically as being at risk performed an exercise test, so the ability of a combination of risk factors to further enhance risk stratification was not clear. Krone et al also noted that inability to exercise carried a bad prognosis, whereas among their exercised patients the majority of deaths occurred in the group with a history of pulmonary congestion on the chest $x$ ray, particularly when this was associated with an inadequate blood pressure response or poor exercise ability. ${ }^{7}$

In our population the Norris index alone was an insensitive marker of subsequent risk, regardless of the exercise test result. This is consistent with the findings of Krone et al who noted that age and past history, both components of the Norris index, were of little added value as risk markers in patients with positive exercise tests after myocardial infarction. ${ }^{7}$ Norris $e t$ al found age to be an important prognostic marker. ${ }^{4}$ They had no upper age limit for inclusion in their study, however, and a high proportion of the patients were older than 66 , the upper limit for inclusion in the current study.

\section{CLINICAL IMPLICATIONS}

In a large population of infarct survivors, we have demonstrated that by integrating the results of clinical evaluation of the patient, routine diagnostic investigations, and pre-discharge exercise testing we could identify $67 \%$ with a very low incidence of subsequent cardiac events. In keeping with the results of Krone et al and the Coronary Artery Surgery Study, ${ }^{715}$ this group of patients would be extremely unlikely to benefit from further investigations. Patients who were unable to perform a predischarge exercise test, particularly those with severe left ventricular damage and reciprocal changes on the electrocardiogram, had a poor prognosis-almost certainly due to gross left ventricular dysfunction. In the absence of evidence of reversible ischaemia, it seems unlikely that patients in this group would benefit from revascularisation. Dipyridamole-thallium-201 scintigraphy might possibly have a role in identifying a subgroup of non-exercised patients with reversible ischaemia who would benefit from grafting. ${ }^{16}$ This hypothesis has not yet been examined. Finally, we were able to identify a small group of 63 patients with reciprocal changes and severe left ventricular damage who also had evidence of reversible ischaemia on exercise testing. This group contained 18 of the 27 exercised patients who died or had a reinfarction during the next year. The patients in this group with exercise induced angina pectoris or who were judged unlikely to tolerate $\beta$ blockade were particularly at risk. It is possible that such patients might benefit from more rigorous medical treatment or even elective surgical treatment. ${ }^{17}$

\section{References}

1 Geltman EM, Ehsani AA, Campbell MK, et al. The influence of location and extent of myocardial infarction on long term ventricular dysrhythmia and mortality. Circulation 1979;60:805-14.

2 Taylor G, O'Neal J, Mellitts E. Prediction of clinical course, coronary anatomy and left ventricular function after recovery from an acute myocardial infarction. Circulation 1980;9:60-70.

3 De Feyter PJ, Eengie MJ, Dighton DH, Visser FC, De Jong A, Roos JP. Prognostic value of exercise testing, coronary angiography and left ventriculography, 6-8 weeks after myocardial infarction. Circulation 1982;66:527-36.

4 Norris RM, Caughey DE, Mercer CJ, Deeming LW, Scott PJ. Coronary prognostic index for predicting survival after recovery from acute myocardial infarction. Lancet 1970;ii:485-8.

5 DeBusk RF, Kraemer HC, Nash E. Stepwise risk stratification soon after acute myocardial infarction. Am f Cardiol 1983;52:1161-6.

6 Theroux P, Waters DD, Halphen C, Debaisieux JC, Mizgala HF. Prognostic value of exercise testing soon after myocardial infarction. $N$ Engl $\mathcal{f}$ Med 1979;301:341-5.

7 Krone RJ, Gillespie JA, Weld FM, Miller JP, Moss AJ. Low-level exercise testing after myocardial infarction: usefulness in enhancing clinical risk stratification. Circulation 1985;71:80-9.

8 Hlatky MA, Califf RM, Lee KL, Pryor DB, Wagner GS, Rosati RA. Prognostic significance of precordial ST segment depression during inferior acute myocardial infarction. Am $\mathcal{f}$ Cardiol 1985;55:325-9.

9 Medias JE, Chahine RA, Goslin R, Blocklow DJ. A comparison of transmural and non-transmural acute myocardial infarction. Circulation 1974;49:498-507.

10 Naughton JP, Hellerstein HK. Exercise testing and ex- 
ercise training in coronary heart disease. New York: Academic Press, 1973.

11 Sobel BE, Bresnahan GF, Shell WE, Yoder RD. Estimation of infarct size in man and its relation to prognosis. Circulation 1972;46:640-8.

12 Jennings $\mathrm{K}$, Reid DS, Hawkins T, Julian DJ. Role of exercise testing early after myocardial infarction in identifying candidates for coronary surgery. $\mathrm{Br} \mathrm{Med}$ f 1984;288:185-7.

13 Sami M, Kraemer H, DeBusk RF. The prognostic significance of serial exercise testing after myocardial infarction. Circulation 1979;60:1238-46.

14 Norwegian Multicentre Study Group. Timololinduced reduction in mortality and reinfarction in patients surviving acute myocardial infarction. $N=$ Engl f Med 1981;304:801-7.

15 CASS Principal Investigators and their Associates. Coronary artery surgery study (CASS): a randomized trial of coronary artery bypass surgery: survival data.O Circulation 1983;68:939-48.

16 Leppo JA, O'Brien J, Rothendler JA, Getchell JD, Lee⿳亠丷厂 VW. Dipyridamole-thallium-201 scintigraphy in the $\overparen{\Phi}$ prediction of future cardiac events after acute myocardial infarction. $N$ Engl f Med 1984;310:1014-8.

17 Bonow RO, Kent KM, Rosing DR, et al. Exercise- $\vec{\circ}$ induced ischaemia in mildly symptomatic patients with coronary artery disease and preserved left ven- $\vec{\omega}$ tricular function. $N$ Engl f Med 1984;311:1339-45. 